\title{
CADERNOS DO PROGRAMA DE PÓS-GRADUAÇÃO EM DIREITO - PPGDir./UFRGS
}

UNIVERSIDADE FEDERAL DO RIO GRANDE DO SUL

Número II Setembro 2004 


\section{CADERNOS DO PROGRAMA}

\section{DE PÓS-GRADUAÇÃo}

\section{EM DIREITO - PPGDIR./UFRGS}

UNIVERSIDADE FEDERAL DO RIO GRANDE DO SUL

Número 2 - Setembro/Z004 


\section{UNIVERSIDADE FEDERAL DO RIO GRANDE DO SUL}

Prof. Dr. José Carlos Perra Hennemann - Reitor

Prot. Dr, Pedro Cezar Dutra Fonseca -- Vice-Reitor

\section{FACULDADE DE DIREITO}

Prof. Pínio de Oliveina Corrêa -... Diretor:

Prof. Séruio josé Porto - Vicew Diretor

\section{DIRETORA}

Profa. Dra, Cláudia Lima Margues
CoOrdenadora do Volume

Profa. Dra. Cládia Lima Marques

ACADÉMICOS RESPONSK VEIS

Silvio Javier Battello

Marcus Vinicius Madeira

SECretráta Extecuttya

Ellane Kusbick

\section{CONSELHO EDITORIAL}

Prof. Almiro do Couto e Silva

Prof. Dr. Carlos Alberto Alvaro de Oiveja

Prof. Dt. Cezar Saldasha Souza Junior

Profa. Dra. Claudia Lima Marques

Prof, Dr. Cláudio I'ortunato Michelon Jr.

Prof. Franz August Gernot Jippert

Prof. Dr. Humberto Bergman Avila

Prof. Dr. José Alcebiades de Oliveira Jr.

Rep. Dis. Juliana I Lete Ribeiro do Vale
Prof, Dr. Francisco Araújo Santos

Prof. Dr. Juís Afonso Heck

Prof. Dr. Luiz Fernando Baxzotto

Prota. Dra. Martha Jucia Oivar Jimenez

Prof. Dr. Peter Walter Ashton

Prof. Dr. Raúl Enrique Rojo

Prof. Dr. Rui Portanova

Prof. Sértio José porto

\section{DADOS INTERNACIONAIS DE CATALOGAÇÃO NA PUBLICAÇÃO (CIP)}

Cadernos do Programa de Pós-Graduação em Direjo - PfPGDir./UFrgS. Número 2. Set/2004

Porto Alegre PPGDir./UFRGS, 2004.

256 p.; $21,0 \times 14,0 \mathrm{~cm}$

ISSN $1678-5029$

Semestral

1. Direiro: Periódicos. 2. Universidade Federal do Rio Grande do Sul

Tiragens: 500 exemplates

Bibliotecátia responsável: Naila Toguinho

Os cadenos do Programa de Pós.Gradunçấo em Direito - PPPDir./UFRGS é umáa publicação semestral, elaborado pelo Programa de Pós-Graduação en Direito, da Faculdade de Direito da Universidade Federal do Rio Grande do Sul. Todos os direitos são reservados, nerhuma parte pode ser reproduzida ou transmitida sob quaisquer mejos, sejam mecanicos ou eletrônicos, incluindo a fotocópia de qualquer infornação sem a prévia autorkzação.

O Consetho Editorial näo assume a responsabilidade por qualquer material publicado nesta revista. Os trabalhos publicados representam o pensamento de seus autores.

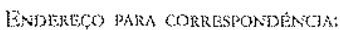

PKOGRAMA DE POS-GRADUACAO EM DIREITO

Faculdade de Direito - UFr GS

Av joão Pessoa, 80 - 2" andar

Porto Akgre - RS - 90040-000

Fone: 513316 3306 - Fonc/Fax: $513316-3987$

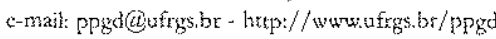

\author{
Pede-se' perninta \\ Predere cassife \\ W ask exchonge \\ On demande enhange \\ W'ir bitlen wn atflatiscts \\ Si risbiade to scambio
}




\section{SUMÁRIO}

PRIMEIRA PARTE: Direito do Estado e Teoria do Direito

Direito do Estado

Organizações da Sociedade Civil de Interesse Público:

Uma nova forma de parceria?

Cristina Barcelos

Teoria do Direito

Direito e justiça em Derrida e Levinas

Cláudio Ari Mello.

Direito Internacional

O protocolo de Olvos para a solução de controvérsias no Mercosul:

Um avanço institucional?

Alessandra Lehmen

SEGUNDA PARTE: Direito Privado e Processual

Direito Privado

A Revisão do contrato: a lesão como quebra do sinalgma genético

Laura Coradini Frantz

Visão internacional do Novo Código Civil

Silvia Dias da Costa Machado.

Direito Processual

Processo e cultura: praxismo, processualismo e formalismo em

Direito Processual Civil

Daniel Francisco Mitidiero

TERCEIRA PARTE: Inserção Internacional*

Poderes del juez y visión cooperativa del processo

C. A. Alvaro de Oliveira

A boa-fé no Código Civil do Quebéc: do geral ao particular

Louise Rolland 165

* Eventos intetnacionais, attigos e palestras de professores estrangeiros e de docentes e discentes da casa publicados no exterior. 
As distinções jurídicas dos procedimentos de assinatura

Alexander Roßnagel

QUARTA PARTE: Teses de Doutorado e Dissertações de Mestrado

\section{TESES DE DOUTORADO}

A Construção de um Direito Internacional na Concorrência: Experiências, Tendências e Rumos Principiológicos

Frederico do Valle Magalhães Marques ................................ 207

A Extradição no Alvorecer do Século XXI

Florisbal de Souza Del'olmo

\section{DISSERTAÇÕES DE MESTRADO}

A Atuação de Ofício do Juiz no Julgamento do Mérito

Maristela da Silva Alves

A Informação como Direito do Consunidor

Fernanda Nunes Barbosa

Breve Análise Estrutural no Negócio Jurídico de Enprego

Alexandre Corrêa da Cruz

Conceitos e Competências Tributárias

Andrei Pitten Velloso

Fundamentos Conceituais para uma Sociologia da Dogmática Jurídica

Cristiano Estrela da Silva

O Fundamento Legal da Alteração Judicial dos Juros nos Contratos de

Crédito Bancário

Carlos Cini Marchionatti

O Direito Fundamental ao Ambiente Como Direito A Prestações en Sentido Amplo Anizio Pires Gavião Filho

\section{ESPECIAI.}

Reflexões Interdisciplinates sobre a Pesquisa de Pós-graduação na Área do Direito:

Un Exercício de Auto-avaliação do PPGdir da UFRGS

Prof. Dr. Francisco de Araujo Santos

Profa. Dra. Claudia Lima Marques 